Review

\title{
Targeting the Endocytic Pathway and Autophagy Process as a Novel Therapeutic Strategy in COVID-19
}

\author{
Naidi Yang1, Han-Ming Shen ${ }^{2}$ \\ 1. Key Laboratory of Flexible Electronics (KLOFE) \& Institute of Advanced Materials (IAM), Nanjing Tech University (NanjingTech), 30 South Puzhu Road, \\ Nanjing, Jiangsu Province 211800, China \\ 2. Faculty of Health Sciences, University of Macau, Macau SAR, China \\ $\square$ Corresponding authors: Naidi Yang: iamndyang@njtech.edu.cn or Han-Ming Shen: hmshen@um.edu.mo
}

(c) The author(s). This is an open access article distributed under the terms of the Creative Commons Attribution License (https://creativecommons.org/licenses/by/4.0/). See http://ivyspring.com/terms for full terms and conditions.

Received: 2020.03.01; Accepted: 2020.03.03; Published: 2020.03.15

\begin{abstract}
Coronaviruses (CoVs) are a group of enveloped, single-stranded positive genomic RNA viruses and some of them are known to cause severe respiratory diseases in human, including Severe Acute Respiratory Syndrome (SARS), Middle East Respiratory Syndrome (MERS) and the ongoing coronavirus disease-19 (COVID-19). One key element in viral infection is the process of viral entry into the host cells. In the last two decades, there is increasing understanding on the importance of the endocytic pathway and the autophagy process in viral entry and replication. As a result, the endocytic pathway including endosome and lysosome has become important targets for development of therapeutic strategies in combating diseases caused by CoVs. In this mini-review, we will focus on the importance of the endocytic pathway as well as the autophagy process in viral infection of several pathogenic CoVs inclusive of SARS-CoV, MERS-CoV and the new CoV named as severe acute respiratory syndrome coronavirus 2 (SARS-CoV-2), and discuss the development of therapeutic agents by targeting these processes. Such knowledge will provide important clues for control of the ongoing epidemic of SARS-CoV-2 infection and treatment of COVID-19.
\end{abstract}

Key words: Coronaviruses, endocytic pathway, autophagy, SARS-CoV-2, COVID-19

\section{Brief introduction of the new coronaviruses}

Coronaviruses (CoVs) are enveloped viruses with a long single-stranded RNA ranging from 26 to 32 kilobases $(\mathrm{kb})$ in size [1]. CoVs belong to the family Coronaviridae in the order Nidovirales, and have been organised into 3 groups: $\alpha-\mathrm{CoVs}, \beta-\mathrm{CoVs}$, and $\gamma-\mathrm{CoVs}$ [2]. Two of the $\beta-\mathrm{CoVs}$ including severe acute respiratory syndrome coronavirus (SARS-CoV) and Middle East respiratory syndrome coronavirus (MERS-CoV) caused severe acute respiratory disease outbreaks in China in 2002-2003 and in the Middle East in 2012, respectively [3].

In December 2019, a novel CoV outbreak, identified and named as severe acute respiratory syndrome coronavirus 2 (SARS-Cov-2) started in Wuhan, Hubei province, China. The SARS-CoV-2 spread very quickly in China and then to the many other countries, causing coronavirus disease-19 (COVID-19). The clinical futures of COVID-19 mainly include fever, cough and pneumonia [4]. Up to date, it has already infected more than 90,000 people worldwide and killed more than three thousand patients, mainly in Wuhan, China. SARS-Cov-2 shares a high sequence identity (around 80\%) with SARS$\mathrm{CoV}$ and a $96.2 \%$ sequence identity with BatCoV RaTG13, a bat CoV [5]. Although some initial cases were linked to a local seafood market in Wuhan, its origin, intermediate hosts and how it was transmitted to humans are still largely unknown [4].

In this mini-review, we will mainly focus on $\beta-\mathrm{CoV}$, which is inclusive of SARS-CoV, MERS-CoV, and the current emerging SARS-CoV-2 to discuss the implication of the endocytic pathway and autophagy process in the infection of these pathogenic CoVs and therapeutic potential of targeting these processes. This review will also include the well-studied mouse hepatitis virus (MHV) since it is often used as a safe mode to study $\mathrm{CoV}$ infection. 


\section{Brief introduction of the autophagy and the endocytic pathway}

Macroautophagy or autophagy refers to an evolutionarily conserved process in which the intracellular components such as protein aggregates and damaged organelles are engulfed into a double-membrane structure called autophagosome, which eventually fuses with lysosome to form autolysosome for degradation [6, 7] (Figure 1). The whole autophagy process is controlled by a group of proteins encoded by autophagy-related-genes (ATGs) in several consecutive stages $[8,9]$. First, the induction or initiation stage is controlled by the ULK1/Atg1 complex, downstream of the mechanistic target of rapamycin complex 1 (mTORC1). Second, the nucleation/expansion/elongation stage is mediated by the ATG14-Beclin1-hVPS34/class III phosphatidylinositol 3-kinases (PI3K) complex, as well as the two ubiquitin-like conjugation systems (ATG5-ATG12 and LC3/ATG8). The third and last stage of autophagy is the maturation/fusion/degradation in which autophagosome fuses with lysosome to form autolysosome where the luminal contents are degraded (Figure 1). At present, the biological functions of autophagy have been extensively studied. Autophagy plays an important role in various physiological and pathological processes, including cell survival, cell death, aging, immunity and metabolism [10, 11]. More importantly, accumulating evidence has highlighted the importance of autophagy in many human diseases, such as cancer, neurodegenerative diseases,

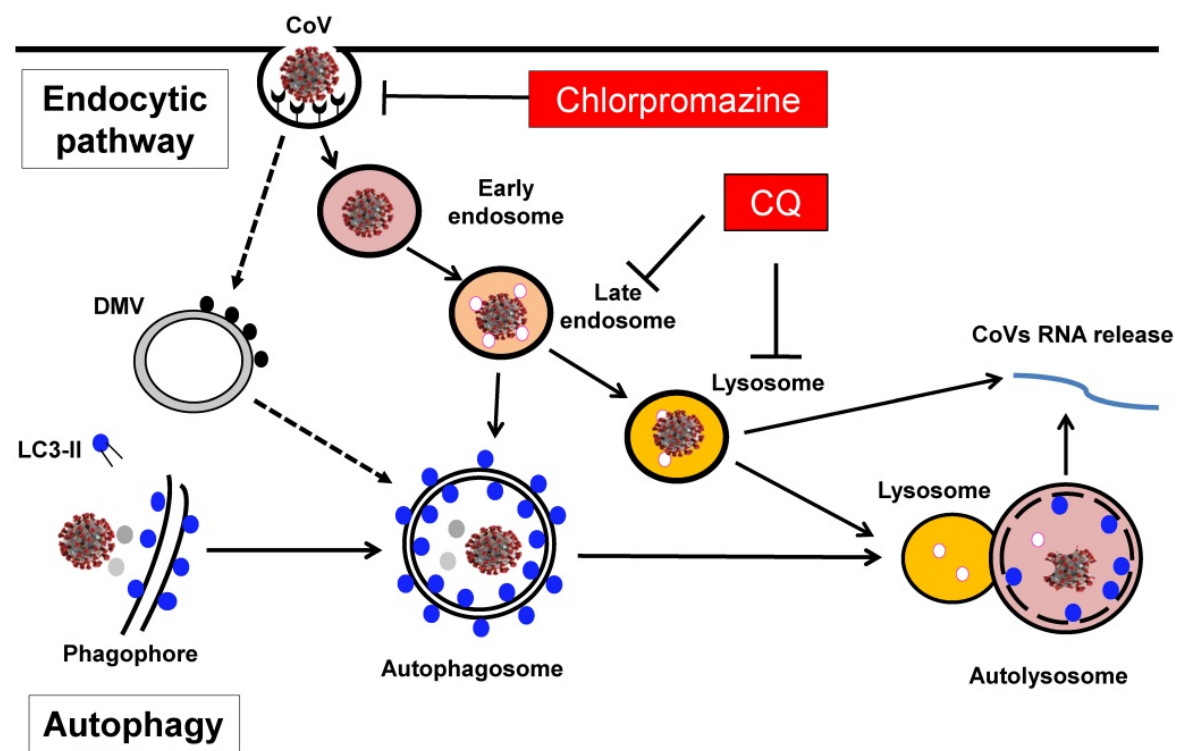

Figure 1. Involvement of the endocytic pathway and autophagy in the entry and replication of CoVs in host cells. Entry of CoVs into the host cells is mainly mediated by the endocytic pathway, meanwhile the autophagy has also been implicated in the viral replication in the cells, a process partly related to the formation of DMV in the host cells. As a result, several groups of inhibitors including the lysosomotropic agents such as CQ and inhibitors for clathrin-mediated endocytosis such as chlorpromazine have been proposed to have therapeutic efficacy against CoVs-induced diseases including COVID-19. metabolic disorders, as well as immunity and infection $[12,13]$. Among them, the implication of autophagy in viral infection has also been widely investigated and deeply appreciated.

In the course of autophagy, lysosome plays an essential role in the maturation/degradation stage of autophagy, as the contents in the autophagosomes are eventually degraded by lysosomes, via autophagosome-lysosome fusion [14-16]. Lysosome, first discovered by the Nobel laureate Christian de Duve in the 1950s, is the most important digestive organelle present in almost all eukaryotic cells and with an array of important biological functions, including endocytosis, exocytosis, macropinocytosis, plasma membrane repair, defense against pathogens, cell death, signal transduction, and autophagy [14, 17]. Lysosome is featured by its acidic internal $\mathrm{pH}$ which is generated by the action of a V-ATPase, a proton-pumping membrane protein complex [18]. Lysosome contains more than 50 acid hydrolases, including proteases, peptidases, phosphatases, nucleases, glycosidases, sulfatases, and lipases designated for all types of macromolecules [19].

On the other hand, lysosome is also a key component of the endocytic pathway, also termed as the endolysosomal network [20] (Figure 1). In addition to autophagy as described above, lysosome receives cargos from other processes including endocytosis through the endocytic pathway. Briefly, following endocytosis, internalized cargos first enter the early endosomes (EE) where the cargos are sorted for two destinations: they are either retrieved for recycling to the plasma membrane/the secretory pathway, or are delivered to the late endosome (LE) and then fuse with lysosome for degradation [20, 21]. The main biological functions of the endocytic pathway are for retrieval and recycling of internalized cargo proteins, and such functions are known to play critical roles in the pathology of important human diseases, in particularly neurodegenerative diseases and viral infection [22, 23].

\section{Implication of autophagy in CoVs infection}

In the past one and a half decades, the implication of autophagy in $\mathrm{CoV}$ infection has attracted substantial attention, 
probably due to the SARS outbreak in 2002-2003 and the emerging field of autophagy research at the same period. At present, various reports have converged onto two important questions: whether $\mathrm{CoV}$ induces autophagy and whether the autophagy machinery or ATG proteins are involved in the infection and replication of CoVs. The first report demonstrating the involvement of autophagy in viral replication was based on MHV [24], in which the authors made several important observations. First, MHV induced the formation of double-membrane vesicles (DMVs), with resemblance to autophagosome, a hallmark of autophagy. Second, the viral replication complexes at DMVs co-localized with the autophagy proteins, LC3 and ATG12. Third and more importantly, MHV replication was impaired in ATG5 knockout embryonic stem cells. Therefore, the authors concluded that autophagy is implicated in the formation of DMV as well as in the replication of MHV [24]. In a follow-up study, the same group also examined the SARS-CoVs and found similar colocalization of the key viral replication proteins with endogenous LC3, a protein marker for autophagosome [25], suggesting a similar function of autophagy in the replication of SARS-CoVs. Cottam et al used another CoV (infectious bronchitis virus, IBV) and found that one of the key viral replicase protein nsp6 is capable of inducing autophagy [26]. Notably, this nsp6 also presents in MHV and SARS-CoV, and thus it would be of interest to further test the effects of nsp6 in these two CoVs on autophagy.

However, several subsequent studies have challenged the notion that autophagy is implicated in $\mathrm{CoV}$ infection. For instance, in Vero cells infected with SARS-CoVs, Snijder et al failed to detect colocalization of LC3 or GFP-LC3 with the viral replication- transcription complexes of SARS-CoV examined using immunofluorescence staining [27]. Further studies also demonstrated that either ATG5 or ATG7, two of the key autophagy proteins in control of autophagosome biogenesis, is not required for viral replication in cells infected by MHV [28, 29] or by SARS-CoVs [30]. In those studies, cells with deletion of either ATG5 or ATG7 failed to impair the viral replication rate. Similarly, virus infection was not inhibited by the knockdown of ATG5 [26]. Thus, all these observations suggest that the autophagy machinery is not directly implicated in the viral replication process.

Intriguingly, there is evidence suggesting the possible inhibitory effect of $\mathrm{CoV}$ on the autophagy process. For instance, a study using SARS-CoV and MERS-CoV in HEK293T, HeLa and MCF-7 cells found that overexpression of membrane-associated papainlike protease PLP2 (PLP2-TM) of SARS-CoV and MERS-CoV led to blockage of autophagosomeslysosomes fusion and suppression of the autophagic flux [31]. Consistently, a more recent report found that MERS-CoV blocks the fusion of autophagosomes and lysosomes and induction of autophagy reduces the replication of MERS-CoV [32]. Thus, it appears that there is certain type of interplay between the autophagy machinery and CoVs, and the exact nature of such interaction remains to be further elucidated.

Taken together, as summarized in Table 1, it is still controversial whether and how autophagy is implicated in the infection of CoVs. The discrepancies in the literature is probably due to the different viruses used, different cells tested and even the different techniques used in study of autophagy. More work is thus needed to clarify those important issues.

Table 1. Implication of autophagy in the infection of CoVs

\begin{tabular}{|c|c|c|c|c|}
\hline Type of Coronavirus tested & $\begin{array}{l}\text { Autophagy machinery } \\
\text { tested }\end{array}$ & Infected Cells/Organs & Main findings & Refs \\
\hline $\begin{array}{l}\text { Mouse } \\
\text { hepatitis virus (MHV) }\end{array}$ & $\begin{array}{l}\text { LC3 } \\
\text { ATG12 }\end{array}$ & $\begin{array}{l}\text { DBT cells } \\
\text { Mouse embryonic stem cell }\end{array}$ & Autophagy machinery are required for MHV replication & {$[24]$} \\
\hline SARS-CoV & Endogenous LC3 & Vero E6 cells & $\begin{array}{l}\text { Viral replication-transcription complexes (RTCs) are co-localizing } \\
\text { with endogenous LC3 }\end{array}$ & {$[25]$} \\
\hline SARS-CoV & $\begin{array}{l}\text { Both Endogenous LC3 } \\
\text { and GFP-LC3 }\end{array}$ & Vero E6 cells & $\begin{array}{l}\text { No evidence are observed for colocalization of LC3 or GFP-LC3 } \\
\text { with the SARS-CoV RTCs }\end{array}$ & {$[27]$} \\
\hline $\begin{array}{l}\text { Mouse } \\
\text { hepatitis virus (MHV) }\end{array}$ & ATG5 & $\begin{array}{l}\text { Mouse embryonic } \\
\text { fibroblasts (MEFs) }\end{array}$ & Deletion of ATG5 does not affect MHV replication & [28] \\
\hline Mouse hepatitis virus (MHV) & ATG7 & $\begin{array}{l}\text { Mouse embryonic } \\
\text { fibroblasts (MEFs) }\end{array}$ & Deletion of ATG7 does not affect MHV replication & [29] \\
\hline Bronchitis virus (IBV) & $\begin{array}{l}\text { ATG5 } \\
\text { LC3 }\end{array}$ & $\begin{array}{l}\text { CHO cell line } \\
\text { MEFs }\end{array}$ & Coronavirus replicase nsp6 protein induces autophagy & [26] \\
\hline SARS-CoV & ATG5 & $\begin{array}{l}\text { Mouse embryonic } \\
\text { fibroblasts (MEFs) }\end{array}$ & SARS-CoV replication is not affected in ATG5 KO MEFs & [30] \\
\hline $\begin{array}{l}\text { Overexpression of membrane- } \\
\text { associated papain-like } \\
\text { protease PLP2 (PLP2-TM) of } \\
\text { SARS-CoV and MERS-CoV }\end{array}$ & $\begin{array}{l}\text { LC3 } \\
\text { Beclin1 }\end{array}$ & $\begin{array}{l}\text { HEK293T, HeLa and MCF-7 } \\
\text { cells }\end{array}$ & $\begin{array}{l}\text { Overexpression of PLP2-TM blocks autophagosomes-lysosomes } \\
\text { fusion } \\
\text { Beclin1 KD partially decreases coronavirus replication }\end{array}$ & [31] \\
\hline MERS-CoV & Beclin1 & Vero B4 & $\begin{array}{l}\text { MERS-CoV) blocks the fusion of autophagosomes and lysosomes } \\
\text { Enhanced autophagy reduces the replication of MERS-CoV }\end{array}$ & {$[32]$} \\
\hline
\end{tabular}


Table 2. Involvement of the endocytic pathway and the respective inhibitors in CoV infection

\begin{tabular}{|c|c|c|c|c|}
\hline Virus and cells tested & Part of endocytic pathway studied & Main findings & Effective inhibitors tested & Refs \\
\hline $\begin{array}{l}\text { MHV/ Mouse L cells, Sac } 2 \text { cells, and } \\
\text { DBT cells }\end{array}$ & Late endosome & $\begin{array}{l}\text { MHV replication machinery co-localizes } \\
\text { with late endosomal membranes }\end{array}$ & NA & {$[44]$} \\
\hline SARS-CoV/Vero E6 cells & $S$ protein-mediated entry & $\begin{array}{l}\text { SARS-CoV entry requires acidification of } \\
\text { endosomes }\end{array}$ & Balfilomycin A1, CQ, NH4Cl & [45] \\
\hline SARS-CoV S glycoprotein/Vero cells & S-protein mediated entry & S-protein mediated entry is $\mathrm{pH}$-dependent & Bafilomycin A1, NH4Cl & [46] \\
\hline SARS-CoV / Vero E6 cells & $\begin{array}{l}\text { Endo-lysosomal } \mathrm{pH} / \text { cysteine } \\
\text { protease }\end{array}$ & $\begin{array}{l}\text { SARS-CoV entry requires acidification of } \\
\text { endosomes }\end{array}$ & $\mathrm{CQ}, \mathrm{NH} 4 \mathrm{Cl}$ & [47] \\
\hline SARS-CoV/Vero cells, 293T cells & $\begin{array}{l}\text { Endo-lysosomal cysteine protease } \\
\text { Cathepsin L }\end{array}$ & $\begin{array}{l}\text { Cathepsin } L \text { is required for infection of cells } \\
\text { with ACE2 expression }\end{array}$ & E64d, Z-FY-DMK & [48] \\
\hline $\begin{array}{l}\text { MHV/Murine fibroblast L2 and } \\
\text { 17CL-1 cells }\end{array}$ & $\begin{array}{l}\text { Endo-lysosomal cysteine protease } \\
\text { Cathepsins }\end{array}$ & $\begin{array}{l}\text { Endosomal proteolysis by cathepsins are } \\
\text { required for viral entry }\end{array}$ & NH4Cl, CQ, Bafilomycin A1 & [49] \\
\hline $\begin{array}{l}\text { MHV/ 17Cl-1 cells, LR-7 cells and } \\
\text { DBT cells }\end{array}$ & Clathrin-dependent endocytosis & $\begin{array}{l}\text { Infection by MHV is sensitive to } \\
\text { lysosomotropic agents and inhibitors of } \\
\text { endocytosis }\end{array}$ & $\begin{array}{l}\text { Chlorpromazine, Bafilomycin } \\
\text { A1, Concanamycin A, NH4Cl, } \\
\text { Monensin }\end{array}$ & {$[50]$} \\
\hline SARS-CoV/HepG2 cells & Clathrin-dependent endocytosis & $\begin{array}{l}\text { Virus entry is mediated by } \\
\text { clathrin-dependent endocytosis }\end{array}$ & Chlorpromazine, $\mathrm{M} \beta \mathrm{CD}$ & [39] \\
\hline SARS-CoV/Vero cells & Late endosome & $\begin{array}{l}\text { Amiodarone inhibits late endosome to } \\
\text { suppress SARS-CoV infection }\end{array}$ & Amiodarone & [51] \\
\hline SARS-CoV/HEK293E cells & $\begin{array}{l}\text { Clathrin- and caveolae-mediated } \\
\text { endocytic pathway }\end{array}$ & $\begin{array}{l}\text { Virus entry is mediated by a clathrin- and } \\
\text { caveolae-independent endocytic pathway }\end{array}$ & NH4Cl, CQ, Bafilomycin A1 & [38] \\
\hline MHV/mouse astrocytoma DHT cells & $\begin{array}{l}\text { Clathrin-or Caveolin-mediated } \\
\text { endocytosis }\end{array}$ & $\begin{array}{l}\text { MHV entry is via clathrin- but not } \\
\text { Caveolin-dependent endocytosis }\end{array}$ & Chlorpromazine & {$[52]$} \\
\hline $\begin{array}{l}\text { MHV and MERS-CoV/ LR7 cells, } \\
\text { HEK293T and Vero cells }\end{array}$ & Clathrin-mediated endocytosis & $\begin{array}{l}\text { Entry of MHV is mediated by lysosomal } \\
\text { proteases, while entry of MERS-CoV is } \\
\text { mediated by furin }\end{array}$ & $\begin{array}{l}\mathrm{NH} 4 \mathrm{Cl}, \mathrm{CQ}, \text { Bafilomycin A1, } \\
\text { Chlorpromazine, Monensin }\end{array}$ & [53] \\
\hline $\begin{array}{l}\text { MHV and MERS-CoV/ LR7 cells, } \\
\text { HEK293T and Vero cells }\end{array}$ & Clathrin-mediated endocytosis & $\begin{array}{l}\text { Cardiotonic steroids ouabain and bufalin } \\
\text { inhibit infection of cells with MHV and } \\
\text { MERS-CoV }\end{array}$ & Ouabain, Bufalin & {$[54]$} \\
\hline $\begin{array}{l}\text { MERS-CoV, SARS-CoV/HEK293T, } \\
\text { A549, HeLa, etc }\end{array}$ & Late endosome-lysosome & $\begin{array}{l}\text { Teicoplanin and derivatives inhibit } \\
\text { Cathepsin L and block viral entry }\end{array}$ & Teicoplanin and derivatives & [55] \\
\hline $\begin{array}{l}\text { MERS-CoV, SARS-CoV/Vero81, } \\
\text { Huh7, and Calu3 cells }\end{array}$ & Endosomal proteases & $\begin{array}{l}\text { Cathepsin L-mediated S protein cleavage } \\
\text { expands virus tropism }\end{array}$ & $\begin{array}{l}\text { E64d, PCI (a proprotein } \\
\text { convertase inhibitor, } \\
\text { dec-RVKR-cmk) }\end{array}$ & [56] \\
\hline SARS-CoV 2/ Vero E6 & Endosomal pH & $\begin{array}{l}\text { SARS-CoV-2 entry requires acidification of } \\
\text { endosomes }\end{array}$ & CQ & [43] \\
\hline
\end{tabular}

\section{Involvement of the endocytic pathway in CoVs infection}

One of the key determining factors in viral infection is the entry of the virus into the host cells. At present, it is widely believed that CoVs enter the host cells via two routes: (i) the endocytic pathway and (ii) non-endosomal pathway [33], as partly illustrated in Figure 1. Among them, the endocytic pathway is considered to be particularly important and has been extensively studied. As discussed earlier, CoVs are enveloped and plus-strand RNA virus and they contain a set of four proteins that encapsidate the viral genomic RNA: the nucleocapsid protein $(\mathrm{N})$, the membrane glycoprotein $(\mathrm{M})$, the envelope protein $(\mathrm{E})$, and the spike glycoprotein (S) [34]. Among them, the function of the $S$ protein is mainly involved in the process of viral entry into the host cells via proteolytic cleavage to form two subunits, S1 and S2 [35]. These two subunits have distinct functions: $\mathrm{S} 1$ is responsible for receptor-binding, while S2 is mainly for membrane fusion and both are essential for viral entry via the endocytic pathway and infection into the host cells.

The first report showing the relevance of endosome-lysosome in CoVs was from a morphological study in which two CoVs (IBV and Porcine Epidemic Diarrhea Virus (PEDV)) were found to accumulate in the lysosomes of cells after infection [36], indicating that the possible functional implication of lysosome in CoVs infection. Subsequent studies have firmly established that the endocytic pathway is the key mechanisms controlling the entry of CoVs into the host cells, and thus the endocytic pathway has been widely investigated as the target of anti-viral therapies, as summarized in Table 2.

Among all these studies, there are several important points to be highlighted. First, different CoVs including MHV, SARS-CoV and MERS-CoV have been consistently demonstrated to engage the endocytic pathway as the main mechanism for viral entry into a variety types of host cells. Among them, clathrin-dependent endocytosis and cathepsinmediated $S$ protein cleavage are two critical steps for the viral entry and infection. In fact, this mechanism is also applicable to many other CoVs such as IBV [37], which is out of the scope of this review.

Second, despite the general understanding for the role of the endocytic pathway for viral entry, there are discrepancies of the exact mechanisms among 
different reports even with the same CoV. For instance, Wang et al found that SARS-CoVs engage clathrin- and caveolae-independent endocytic pathway as the key mechanism for viral entry [38], which is inconsistent with an earlier report in which SARS-CoV entry into HepG2 cells is mostly mediated by the clathrin-dependent pathway [39]. Part of the reason for such discrepancies is the different cell types used in their studies, as shown in Table 2 . Therefore, it is possible that the exact nature of the entry is context-dependent, including the type of the virus and the type of the cells.

Third, at present, the entry mechanisms and the implication of the endocytic pathway of the new emerging SARS-CoV-2 have not been reported directly. It is now known that SARS-CoV-2 utilizes the same receptor of SARS-CoV, which is angiotensin converting enzyme II (ACE2) for viral entry into the host cells [5, 40]. ACE2 transcripts was originally only found in heart, kidney and testis of human [41]. However, it was later found that ACE2 protein expresses abundantly in the epithelia of the human lung and small intestine [42]. Since SARS-CoV-2 also binds to the same ACE2 receptor as SARS-CoV [5] and SARS-CoV-2 is also susceptible to the inhibitory effect of chloroquine (CQ), a lysosomotropic agent [43], it is highly possible that this new $\mathrm{CoV}$ utilizes the same endocytic pathway for entry into the host cells. Understanding this mechanism is important in the search of effective therapeutic agents in the treatment of COVID-19 caused by this new CoV.

Finally, in almost all the studies listed in Table 2, different inhibitors of the endocytic pathway have been used in blocking viral entry and infection. Among them, three groups of inhibitors are believed to be particularly important and clinically relevant. The first group are the lysosomotropic agents which are capable of accumulating inside and neutralizing the endosome-lysosomal acidic $\mathrm{pH}$ and thus blocking the protease activity to inhibit the viral entry. In this group, CQ is an ancient anti-malaria drug and clinically available, as shown in Figure 1. The second group are direct endosomal-lysosomal protease inhibitors such as E64d. And the third group are inhibitors for the clathrin-mediated endocytosis such as chlorpromazine, which is also clinically available (Figure 1). The details of such inhibitors are to be discussed in the section below.

Taken together, establishing the role of endocytic pathway in viral entry is a major breakthrough in the mechanistic understanding of the CoVs infection, which offers great opportunity in development of novel therapeutic strategies for treatment of diseases such as SARS and COVID-19.

\section{Targeting the endocytic pathway and autophagy as a novel therapeutic strategy against CoVs}

\section{Lysosomotropic agents targeting endosomal/ lysosomal pH}

CQ, a well-known anti-malarial drug, is probably the most well-studied lysosomotropic agent that accumulates in the acidic organelles such as endosomes and lysosomes and neutralizes their $\mathrm{pH}$ [57]. At present, it has been well studied that CQ has a wide-spectrum of anti-viral effects including anti-CoVs, anti-HIV, and anti-type A and B influenza viruses [58]. The anti-viral effects of CQ and its analogs have been reviewed elsewhere [59]. Here we would like to focus on the effect of CQ on CoVs, as summarized in Table 2. For instance, CQ has been shown to inhibit MERS-CoV replication in vitro via a screening of an FDA-approved compound library [60]. Treatment with CQ at a clinically relevant concentration, either before or after SARS-CoV infection into the Vero E6 cells, was found to be effective in suppressing viral infection, indicating its application in both prophylactic and therapeutic conditions [47]. Similar results were also found in another lysosomotropic agent, ammonium chloride $\left(\mathrm{NH}_{4} \mathrm{Cl}\right)$ [47]. It is known that the cleavage of the Spike Glycoprotein (S protein) by proteases is required for the SARS-CoV entry to the cells via a $\mathrm{pH}$-dependent manner [45]. Mechanistically, it is believed that the neutralization of endo-lysosomal $\mathrm{pH}$ by $\mathrm{CQ}$ inhibits the protease activities and prevents the cleavage of $S$ protein and subsequently impairs the viral entry into the host cell. Interestingly, Wang et al showed that in cells treated with $\mathrm{CQ}, \mathrm{NH}_{4} \mathrm{Cl}$ or Bafilomycin A1 (an endo/lysosomal V-ATPase inhibitor), the viral receptor ACE2 was trapped within perinuclear vacuoles [38], suggesting that these lysosomotropic agents may also affect the function of ACE2. Since ACE2 serves as the viral receptor for both SARS-CoV and SARS-CoV-2, such observations further support the notion for the potent anti-viral activity of those lysosomotropic agents. Indeed, a very recent study showed that CQ inhibits the SARS-CoV-2 infection at both entry and post-entry stages in Vero E6 cells [43].

In addition to its direct effects on CoVs, there is evidence of the combinational activity of CQ with other therapeutic agents for treatment of SARS, MERS and possibly COVID-19. For instance, He et al reported that $\mathrm{CQ}$ has synergistic effect on glucocorticoid signaling by stabilizing glucocorticoid receptor [61]. Since glucocorticoid is one of the recommended therapy for severe SARS patients [62], it is possible that CQ may can be used for treatment of COVID-19 in combination of glucocorticoids and 
clinical trials are thus needed to test the efficacy of such combined therapy.

At present, CQ phosphate has been listed as a new therapeutic in the sixth version of "Guidelines for the Prevention, Diagnosis, and Treatment of COVID-19" issued by the National Health Commission of the People's Republic of China. And a number of clinical trials with CQ have been initiated in China [63]. The current suggested dosage of CQ for COVID-19 is as high as $500 \mathrm{mg}$, with treatment not exceeding 10 days. However, the usage of CQ phosphate should be evaluated carefully as it may also have side effects such as retinopathy [64] and cautions should be taken for close monitoring of the potential side effect throughout the whole treatment period. The dosage should be reduced or stopped if reduction in haemoglobin concentration, lymphocyte count and platelet count, or the eyesight are observed. In addition, since CQ is the substrate of cytochrome P450 (CYP) enzymes which are responsible for the metabolism of multiple drugs, it might interfere with other medications such as digitoxin (a cardiac glycoside) and tamoxifen (used for treatment of breast cancer). More details of the toxicity and precautious of CQ can be referred elsewhere [65].

\section{Endosomal-lysosomal protease inhibitors}

Cathepsins are endosomal and lysosomal cysteine proteases that play important roles in protein degradation in various cellular processes including both the endocytic pathway and autophagy [64]. The role of cathepsins in viral infection was first identified by Huang et al and they found that one cysteine proteases inhibitor E64d and a specific cathepsin $\mathrm{L}$ inhibitor Z-FY(t-Bu)-DMK are able to block the SARS-CoV infection [48]. K11777 is another cysteine protease inhibitor that has been reported to block the entry of SARS-CoV at the sub-nanomolar range [66]. In addition, teicoplanin, a glycopeptide antibiotic and its derivatives inhibit the entry of MERS-CoV and SARS-CoV by inhibition of cathepsin L activity [55]. Interestingly, a serine protease inhibitor camostat was known to inhibit transmembrane protease serine 2 (TMPRSS2) and effectively protected the mice against death caused by SARS-CoV infection [55]. More importantly, a very recent study showed that camostat can also block the entry of SARS-CoV-2 by inhibiting ACE2 and TMPRSS2 [67]. Since camostat is already in clinical use for the treatment of chronic pancreatitis, suggesting its therapeutic potential for treatment of COVID-19.

\section{Inhibitors for clathrin-mediated endocytosis}

As discussed earlier, clathrin-mediated endocytosis is one of the key mechanisms for viral entry into the host cells, including MHV [50, 52, 54], SARS-CoV [38], and MERS-CoV [53, 54]. Therefore, chlorpromazine, an inhibitor for clathrin-dependent endocytosis, have been consistently found to possess significant inhibitory effect on the entry of those CoVs [39]. In fact, chlorpromazine is a FDA-approved drug widely used for treatment of psychotic disorders such as schizophrenia [68]. Importantly, it has been well established for its antivirus function for many types of viruses, including SARS-CoV and MERS-CoVs, as summarized in Table 2. At present, the clinical application of chlorpromazine in treatment of SARS and MERS has not been reported and it would be of interest to conduct clinical trials for testing the therapeutic effect of chlorpromazine on COVID-19.

In addition, two cardiotonic steroids ouabain and bufalin, selective inhibitors of the plasma membrane $\mathrm{Na}^{+} / \mathrm{K}^{+}$-ATPase, have been shown to inhibit the MERS-CoV infection at nanomolar concentrations via affecting the clathrin-mediated endocytosis pathway [54]. Since both of them are also FDA-approved drugs and clinically available, it would be of interest to test them clinically for treatment of COVID-19.

\section{Summary and perspectives}

The current ongoing epidemic of SARS-CoV-2 and COVID-19 worldwide has emerged as a significant global public health threat. While urgent regulatory measures in control of the rapid spread of this virus are essential, scientists around the world have quickly engaged in this battle by studying the molecular mechanisms and searching for effective therapeutic strategies against this deadly disease. At present, while the exact role of autophagy remains debatable, there is overwhelming evidence suggesting that the endocytic pathway plays a key role in mediating viral entry for many CoVs including SARS-CoVs, MERS-CoVs and possibly SARS-CoV-2. As a result, several inhibitors targeting the endocytic pathway appear to have the therapeutic potential in treatment of COVID-19, including a lysosomotropic agent CQ and a clathrin-mediated endocytosis inhibitor chlorpromazine $[43,63,65,68]$. Since both are FDA-approved and clinically available, clinical trials either as a single therapy or in combination with other anti-viral drugs are much needed.

\section{Competing Interests}

The authors have declared that no competing interest exists.

\section{References}

1. Weiss SR, Navas-Martin S. Coronavirus pathogenesis and the emerging pathogen severe acute respiratory syndrome coronavirus. Microbiol Mol Biol Rev. 2005; 69: 635-64. 
2. Schoeman D, Fielding BC. Coronavirus envelope protein: current knowledge. Virol J. 2019; 16: 69.

3. Zheng Y, Shang J, Yang Y, Liu C, Wan Y, Geng Q, et al. Lysosomal Proteases Are a Determinant of Coronavirus Tropism. J Virol. 2018; 92.

4. Zhu N, Zhang D, Wang W, Li X, Yang B, Song J, et al. A Novel Coronavirus from Patients with Pneumonia in China, 2019. N Engl J Med. 2020; 382: 727-33.

5. Zhou P, Yang XL, Wang XG, Hu B, Zhang L, Zhang W, et al. A pneumonia outbreak associated with a new coronavirus of probable bat origin. Nature. 2020.

6. Mizushima N. A brief history of autophagy from cell biology to physiology and disease. Nat Cell Biol. 2018; 20: 521-7.

7. Levine B, Kroemer G. Biological Functions of Autophagy Genes: A Disease Perspective. Cell. 2019; 176: 11-42.

8. Yin Z, Pascual C, Klionsky DJ. Autophagy: machinery and regulation. Microb Cell. 2016; 3: 588-96.

9. Mizushima N. The ATG conjugation systems in autophagy. Curr Opin Cell Biol. 2019; 63: 1-10.

10. Mizushima N, Levine B. Autophagy in mammalian development and differentiation. Nat Cell Biol. 2010; 12: 823-30.

11. Choi AM, Ryter SW, Levine B. Autophagy in human health and disease. N Engl J Med. 2013; 368: 651-62.

12. Meijer AJ, Codogno P. Autophagy: regulation and role in disease. Crit Rev Clin Lab Sci. 2009; 46: 210-40.

13. Jiang P, Mizushima N. Autophagy and human diseases. Cell Res. 2014; 24: 69-79.

14. Eskelinen EL, Saftig P. Autophagy: a lysosomal degradation pathway with a central role in health and disease. Biochim Biophys Acta. 2009; 1793: 664-73.

15. Shen HM, Mizushima N. At the end of the autophagic road: an emerging understanding of lysosomal functions in autophagy. Trends Biochem Sci. 2014; 39: 61-71.

16. Settembre C, Fraldi A, Medina DL, Ballabio A. Signals from the lysosome: a control centre for cellular clearance and energy metabolism. Nat Rev Mol Cell Biol. 2013; 14: 283-96

17. Lawrence RE, Zoncu R. The lysosome as a cellular centre for signalling, metabolism and quality control. Nat Cell Biol. 2019; 21: 133-42.

18. Mindell JA. Lysosomal acidification mechanisms. Annu Rev Physiol. 2012; 74: 69-86.

19. Lubke T, Lobel P, Sleat DE. Proteomics of the lysosome. Biochim Biophys Acta. 2009; 1793: 625-35.

20. Cullen PJ, Steinberg F. To degrade or not to degrade: mechanisms and significance of endocytic recycling. Nat Rev Mol Cell Biol. 2018; 19: 679-96.

21. Naslavsky N, Caplan S. The enigmatic endosome - sorting the ins and outs of endocytic trafficking. J Cell Sci. 2018; 131.

22. Schreij AM, Fon EA, McPherson PS. Endocytic membrane trafficking and neurodegenerative disease. Cell Mol Life Sci. 2016; 73: 1529-45.

23. Nour AM, Modis Y. Endosomal vesicles as vehicles for viral genomes. Trends Cell Biol. 2014; 24: 449-54.

24. Prentice E, Jerome WG, Yoshimori T, Mizushima N, Denison MR. Coronavirus replication complex formation utilizes components of cellular autophagy. J Biol Chem. 2004; 279: 10136-41

25. Prentice E, McAuliffe J, Lu X, Subbarao K, Denison MR. Identification and characterization of severe acute respiratory syndrome coronavirus replicase proteins. J Virol. 2004; 78: 9977-86.

26. Cottam EM, Maier HJ, Manifava M, Vaux LC, Chandra-Schoenfelder P, Gerner W, et al. Coronavirus nsp6 proteins generate autophagosomes from the endoplasmic reticulum via an omegasome intermediate. Autophagy. 2011; 7: $1335-47$

27. Snijder EJ, van der Meer $Y$, Zevenhoven-Dobbe J, Onderwater JJ, van der Meulen J, Koerten HK, et al. Ultrastructure and origin of membrane vesicles associated with the severe acute respiratory syndrome coronavirus replication complex. J Virol. 2006; 80: 5927-40.

28. Zhao Z, Thackray LB, Miller BC, Lynn TM, Becker MM, Ward E, et al. Coronavirus replication does not require the autophagy gene ATG5. Autophagy. 2007; 3: 581-5.

29. Regoiori F, Monastyrska I, Verheije $\mathrm{MH}$, Cali $\mathrm{T}$, Ulasli $\mathrm{M}$, Bianchi $\mathrm{S}$, et al. Coronaviruses Hijack the LC3-I-positive EDEMosomes, ER-derived vesicles exporting short-lived ERAD regulators, for replication. Cell Host Microbe. 2010; 7: 500-8.

30. Schneider M, Ackermann $\mathrm{K}$, Stuart $\mathrm{M}$, Wex C, Protzer U, Schatzl HM, et al. Severe acute respiratory syndrome coronavirus replication is severely impaired by MG132 due to proteasome-independent inhibition of M-calpain. J Virol. 2012; 86: 10112-22.

31. Chen X, Wang K, Xing Y, Tu J, Yang X, Zhao Q, et al. Coronavirus membrane-associated papain-like proteases induce autophagy through interacting with Beclin1 to negatively regulate antiviral innate immunity. Protein Cell. 2014; 5: 912-27.

32. Gassen NC, Niemeyer D, Muth D, Corman VM, Martinelli S, Gassen A, et al. SKP2 attenuates autophagy through Beclin1-ubiquitination and its inhibition reduces MERS-Coronavirus infection. Nat Commun. 2019; 10: 5770.

33. Zumla A, Chan JF, Azhar EI, Hui DS, Yuen KY. Coronaviruses - drug discovery and therapeutic options. Nat Rev Drug Discov. 2016; 15: 327-47.

34. de Haan CA, Rottier PJ. Molecular interactions in the assembly of coronaviruses. Adv Virus Res. 2005; 64: 165-230.

35. Millet JK, Whittaker GR. Physiological and molecular triggers for SARS-CoV membrane fusion and entry into host cells. Virology. 2018; 517: 3-8.
36. Ducatelle R, Hoorens J. Significance of lysosomes in the morphogenesis of coronaviruses. Arch Virol. 1984; 79: 1-12.

37. Wang H, Yuan X, Sun Y, Mao X, Meng C, Tan L, et al. Infectious bronchitis virus entry mainly depends on clathrin mediated endocytosis and requires classical endosomal/lysosomal system. Virology. 2019; 528: 118-36.

38. Wang H, Yang P, Liu K, Guo F, Zhang Y, Zhang G, et al. SARS coronavirus entry into host cells through a novel clathrin- and caveolae-independent endocytic pathway. Cell Res. 2008; 18: 290-301.

39. Inoue $\mathrm{Y}$, Tanaka N, Tanaka Y, Inoue S, Morita K, Zhuang M, et al. Clathrin-dependent entry of severe acute respiratory syndrome coronavirus into target cells expressing ACE2 with the cytoplasmic tail deleted. J Virol. 2007; 81: 8722-9.

40. Kuba K, Imai Y, Rao S, Gao H, Guo F, Guan B, et al. A crucial role of angiotensin converting enzyme 2 (ACE2) in SARS coronavirus-induced lung injury. Nat Med. 2005; 11: 875-9.

41. Donoghue M, Hsieh F, Baronas E, Godbout K, Gosselin M, Stagliano N, et al. A novel angiotensin-converting enzyme-related carboxypeptidase (ACE2) converts angiotensin I to angiotensin 1-9. Circ Res. 2000; 87: E1-9.

42. Hamming I, Timens W, Bulthuis ML, Lely AT, Navis G, van Goor H. Tissue distribution of ACE2 protein, the functional receptor for SARS coronavirus. A first step in understanding SARS pathogenesis. J Pathol. 2004; 203: 631-7.

43. Wang M, Cao R, Zhang L, Yang X, Liu J, Xu M, et al. Remdesivir and chloroquine effectively inhibit the recently emerged novel coronavirus (2019-nCoV) in vitro. Cell Res. 2020.

44. van der Meer Y, Snijder EJ, Dobbe JC, Schleich S, Denison MR, Spaan WJ, et al. Localization of mouse hepatitis virus nonstructural proteins and RNA synthesis indicates a role for late endosomes in viral replication. J Virol. 1999; 73: 7641-57.

45. Simmons G, Reeves JD, Rennekamp AJ, Amberg SM, Piefer AJ, Bates P. Characterization of severe acute respiratory syndrome-associated coronavirus (SARS-CoV) spike glycoprotein-mediated viral entry. Proc Natl Acad Sci U S A. $2004 ; 101: 4240-5$

46. Yang ZY, Huang Y, Ganesh L, Leung K, Kong WP, Schwartz O, et al. $\mathrm{pH}$-dependent entry of severe acute respiratory syndrome coronavirus is mediated by the spike glycoprotein and enhanced by dendritic cell transfer through DC-SIGN. J Virol. 2004; 78: 5642-50.

47. Vincent MJ, Bergeron E, Benjannet S, Erickson BR, Rollin PE, Ksiazek TG, et al. Chloroquine is a potent inhibitor of SARS coronavirus infection and spread. Virol J. 2005; 2: 69 .

48. Huang IC, Bosch BJ, Li F, Li W, Lee KH, Ghiran S, et al. SARS coronavirus, but not human coronavirus NL63, utilizes cathepsin L to infect ACE2-expressing cells. J Biol Chem. 2006; 281: 3198-203.

49. Qiu Z, Hingley ST, Simmons G, Yu C, Das Sarma J, Bates P, et al. Endosomal proteolysis by cathepsins is necessary for murine coronavirus mouse hepatitis virus type 2 spike-mediated entry. J Virol. 2006; 80: 5768-76.

50. Eifart P, Ludwig K, Bottcher C, de Haan CA, Rottier PJ, Korte T, et al. Role of endocytosis and low $\mathrm{pH}$ in murine hepatitis virus strain A59 cell entry. J Virol. 2007; 81: 10758-68.

51. Stadler K, Ha HR, Ciminale V, Spirli C, Saletti G, Schiavon M, et al. Amiodarone alters late endosomes and inhibits SARS coronavirus infection at a post-endosomal level. Am J Respir Cell Mol Biol. 2008; 39: 142-9.

52. $\mathrm{Pu} \mathrm{Y}$, Zhang $\mathrm{X}$. Mouse hepatitis virus type 2 enters cells through a clathrin-mediated endocytic pathway independent of Eps15. J Virol. 2008; 82: 8112-23.

53. Burkard $\mathrm{C}$, Verheije $\mathrm{MH}$, Wicht $\mathrm{O}$, van Kasteren SI, van Kuppeveld FJ, Haagmans BL, et al. Coronavirus cell entry occurs through the endo-/lysosomal pathway in a proteolysis-dependent manner. PLoS Pathog. 2014; 10: e1004502.

54. Burkard C, Verheije MH, Haagmans BL, van Kuppeveld FJ, Rottier PJ, Bosch BJ, et al. ATP1A1-mediated Src signaling inhibits coronavirus entry into host cells. J Virol. 2015; 89: 4434-48.

55. Zhou N, Pan T, Zhang J, Li O, Zhang X, Bai C, et al. Glycopeptide Antibiotics Potently Inhibit Cathepsin L in the Late Endosome/Lysosome and Block the Entry of Ebola Virus, Middle East Respiratory Syndrome Coronavirus (MERS-CoV), and Severe Acute Respiratory Syndrome Coronavirus (SARS-CoV). J Biol Chem. 2016; 291: 9218-32.

56. Park JE, Li K, Barlan A, Fehr AR, Perlman S, McCray PB, Jr., et al. Proteolytic processing of Middle East respiratory syndrome coronavirus spikes expands virus tropism. Proc Natl Acad Sci U S A. 2016; 113: 12262-7.

57. Degtyarev M, De Maziere A, Orr C, Lin J, Lee BB, Tien JY, et al. Akt inhibition promotes autophagy and sensitizes PTEN-null tumors to lysosomotropic agents. J Cell Biol. 2008; 183: 101-16.

58. Savarino A, Di Trani L, Donatelli I, Cauda R, Cassone A. New insights into the antiviral effects of chloroquine. Lancet Infect Dis. 2006; 6: 67-9.

59. Al-Bari MAA. Targeting endosomal acidification by chloroquine analogs as a promising strategy for the treatment of emerging viral diseases. Pharmacol Res Perspect. 2017; 5: e00293.

60. de Wilde AH, Jochmans D, Posthuma CC, Zevenhoven-Dobbe JC, van Nieuwkoop S, Bestebroer TM, et al. Screening of an FDA-approved compound library identifies four small-molecule inhibitors of Middle East respiratory syndrome coronavirus replication in cell culture. Antimicrob Agents Chemother. 2014; 58: 4875-84.

61. $\mathrm{He} Y, \mathrm{Xu}_{\mathrm{Y}}$, Zhang $\mathrm{C}$, Gao X, Dykema KJ, Martin KR, et al. Identification of a lysosomal pathway that modulates glucocorticoid signaling and the inflammatory response. Sci Signal. 2011; 4: ra44. 
62. Nie $\mathrm{QH}$, Luo $\mathrm{XD}$, Hui WL. Advances in clinical diagnosis and treatment of severe acute respiratory syndrome. World J Gastroenterol. 2003; 9: 1139-43.

63. Gao J, Tian Z, Yang X. Breakthrough: Chloroquine phosphate has shown apparent efficacy in treatment of COVID-19 associated pneumonia in clinical studies. Biosci Trends. 2020.

64. Schrezenmeier E, Dorner T. Mechanisms of action of hydroxychloroquine and chloroquine: implications for rheumatology. Nat Rev Rheumatol. 2020; 16: $155-66$.

65. multicenter collaboration group of Department of S, Technology of Guangdong P, Health Commission of Guangdong Province for chloroquine in the treatment of novel coronavirus p. [Expert consensus on chloroquine phosphate for the treatment of novel coronavirus pneumonia]. Zhonghua Jie He He Hu Xi Za Zhi. 2020; 43: E019.

66. Zhou Y, Vedantham P, Lu K, Agudelo J, Carrion R, Jr., Nunneley JW, et al. Protease inhibitors targeting coronavirus and filovirus entry. Antiviral Res. 2015; 116: 76-84.

67. Hoffmann M, Kleine-Weber H, Schroeder S, Krüger N, Herrler T, Erichsen S, et al. SARS-CoV-2 cell entry depends on ACE2 and TMPRSS2 and is blocked by a 2 clinically-proven protease inhibitor Cell. 2020; [Epub ahead of print].

68. Boyd-Kimball D, Gonczy K, Lewis B, Mason T, Siliko N, Wolfe J. Classics in Chemical Neuroscience: Chlorpromazine. ACS Chem Neurosci. 2019; 10: 79-88. 